\title{
Anticardiolipin antibodies and coronary heart disease
}

\author{
D. A. Tsakiris*, G. A. MarbeT*, F. Burkart $\dagger^{*}$ And F. DuckerT* \\ ${ }^{*}$ Coagulation and Fibrinolysis Laboratory, and $\dagger$ Department of Internal Medicine, Division of Cardiology, University \\ Clinics, Kantonsspital Basel, Switzerland
}

KEY WORDS: Antiphospholipid antibodies, anticardiolipin antibodies, coronary heart disease, myocardial infarction.

Arterial or venous thrombotic events have been described as complications in patients with positive anticardiolipin antibodies ( $a C L)$, affecting various organs including the heart. In order to see whether aCL could be, among others, a predisposing factor for coronary artery occlusions and whether it could serve as a prognostic marker for coronary heart disease, 232 patients enrolled in the European Concerted Action on Thrombosis Angina Pectoris Study were studied. aCL and various other haemostatic parameters were determined at time of admittance in order to see whether a relationship existed between haemostasis at baseline and extent or prognosis of the cardiovascular disease. A follow-up at 12 and 24 months after angiography included information about relapsing coronary or other thrombotic events, treatment and outcome of the disease. aCL were not found to be a marker of either progressive cardiovascular disease or recurrent thrombotic events. No correlation was found, either in aCL positive or in aCL negative patients, between high levels of haemostasis activation markers, such as $\beta$-thromboglobulin, platelet factor 4 or fibrinopeptide $A$ and recurrent cardiovascular disease.

\section{Introduction}

Lupus anticoagulants and/or anticardiolipin antibodies (aCL) interfere with haemostasis and result in a higher predisposition for thrombosis ${ }^{1.2]}$. These antibodies were primarily described in patients with systemic lupus erythematosus but they also occur in many other autoimmune disorders ${ }^{[3]}$. Arterial or venous thrombotic events have been described as complications in such disorders affecting various organs including the heart, for which episodes of thrombotic endocarditis or coronary artery occlusions have been described ${ }^{[4-6]}$. The aim of this study was to see whether aCL could be, among others, a predisposing factor for coronary artery occlusions and whether they could serve as a prognostic marker for coronary heart disease (CHD).

\section{Patients and methods}

\section{PATIENT RECRUITMENT}

Over a period of 2 years we studied 232 patients (198 men aged $55 \pm 9$ years and 34 women aged $56 \pm 10$ years) with angina pectoris admitted during remission to the Cardiology Department, as outpatients for evaluation of their cardiovascular disease. All underwent coronary angiography. Since they were enrolled in the European Concerted Action on Thrombosis Angina Pectoris Study (ECAT), various haemostatic parameters were also determined at the time of admittance in order to see whether a relationship existed between haemostasis at baseline and extent or prognosis of the cardiovascular disease.

Submitted for publication on 6 January 1992 and in revised form 9 July 1992. Supponed by the Swiss National Science Foundation, research grant NF-3130003.91 .

Correspondence. Dr.med. D. A. Tsakiris, Coagulation and Fibrinolysis Laboratory, Kantonsspital Basel, $\mathrm{CH}-4031$ Basel, Switzerland.
PATIENT HISTORY

Medical history was focused on previous myocardial infarction and/or other thrombotic events as well as current treatment. Chest pain was classified in four categories, namely resting angina, effort angina, other chest pain and no chest pain.

\section{CORONARY ANGIOGRAPHY}

Angiography was carried out following the Judkins technique scoring the left main, the left anterior descending, the circumflex and the right coronary artery in three categories: (a) stenosis less than 50\% in diameter reduction, (b) stenosis between $50 \%$ and less than $100 \%$ and (c) total occlusion $100 \%$. In addition, the ejection fraction $(E F, \%)$ and the left ventricular end diastolic pressure (LVEDP, $\mathrm{mmHg}$ ) were determined.

\section{LABORATORY EXAMINATIONS}

From the general laboratory tests haematocrit, leukocyte count, platelet count, triglycerides and total cholesterol were measured according to classical methods.

Haemostasis screening included activated partial thromboplastin time (APTT), $\beta$-thromboglobulin ( $\beta$-TG), platelet factor 4 (PF4), von Willebrand factor antigen (vWF:Ag), factor VIII activity (VIII:C), fibrinopeptide A (FPA), fibrinogen (Fbg) and euglobulin lysis time (ELT) before and after a $10 \mathrm{~min}$ venous stasis. All were determined according to known methods standardized by the steering committee for quality control of the ECAT study $[7]$.

Anticardiolipin IgG, IgM and IgA antibodies were measured with a commercial kit (QUANTA Lite ACA by Inova Diagnostics Inc, U.S.A.). The method uses an enzyme-linked immunoassay based on the one described by Harris et al., giving the results in arbitrary GPL, MPL 
Table 1 Means and standard deviations of various laboratory parameters in 232 patients

\begin{tabular}{|c|c|c|c|c|}
\hline & $\begin{array}{l}\mathrm{aCL}_{\text {pos }} \\
(\mathrm{n}=35)\end{array}$ & $\begin{array}{l}\text { aCL neg } \\
(\mathrm{n}=197)\end{array}$ & $\begin{array}{c}\text { Normal } \\
\text { values }\end{array}$ & M-W \\
\hline Age (years) & $55 \cdot 3+9 \cdot 0$ & $55 \cdot 0+8 \cdot 7$ & - & ns \\
\hline Weight $(\mathrm{kg})$ & $79.2 \pm 11.9$ & $75 \cdot 8 \pm 11 \cdot 1$ & - & ns \\
\hline Ejection fraction (\%) & $63 \cdot 2 \pm 12 \cdot 2$ & $63.9 \pm 12.6$ & $>55$ & ns \\
\hline LVEDP $(\mathrm{mmHg})$ & $17 \cdot 4+8 \cdot 2$ & $177+6.8$ & $<15$ & ns \\
\hline Haematocrit (\%) & $42.9 \pm 8 \cdot 1$ & $43.2 \pm 3.6$ & $37-53$ & ns \\
\hline Leukocytes $\left(\times 10^{\prime} .1^{-1}\right)$ & $6.4 \pm 1.6$ & $6.9 \pm 4.0$ & $3 \cdot 0-9 \cdot 6$ & ns \\
\hline Platelets $\left(\times 10^{9} \cdot 1^{-1}\right)$ & $245 \cdot 7+74 \cdot 5$ & $250 \cdot 1+605$ & $143-400$ & ns \\
\hline Triglycerides (mmol . $1^{-1}$ ) & $2.4 \pm 1.6$ & $27 \pm 1.9$ & $0.5-2.7$ & ns \\
\hline Cholesterol total (mmol. $\left.\mathrm{l}^{-1}\right)$ & $6.7 \pm 1.0$ & $6 \cdot 5 \pm 1 \cdot 2$ & $3 \cdot 7-7 \cdot 0$ & ns \\
\hline APTT (s) & $59 \cdot 4+29 \cdot 8$ & $51 \cdot 3+16 \cdot 8$ & $38-45$ & ns \\
\hline$\beta$-thromboglobulin (ng. $\mathrm{ml}^{-1}$ ) & $47.6 \pm 27 \cdot 9$ & $45 \cdot 6 \pm 25 \cdot 1$ & $<52$ & ns \\
\hline Platelet factor $4\left(\mathrm{ng} \cdot \mathrm{ml}^{-1}\right)$ & $8.6 \pm 9.0$ & $8.9 \pm 17.0$ & $<10.4$ & ns \\
\hline VIII:C $(\%)$ & $145+43$ & $135 \pm 41$ & $49-226$ & ns \\
\hline vWF:Ag (\%) & $140 \pm 47$ & $138 \pm 52$ & $49-226$ & ns \\
\hline Fibrinopeptıde A (ng. $\mathrm{ml}^{-1}$ ) & $5 \cdot 0 \pm 10 \cdot 4$ & $4 \cdot 5 \pm 14 \cdot 3$ & $<2-0$ & ns \\
\hline Fibnnogen $\left(\mathrm{g} .1^{-1}\right)$ & $2.41 \pm 0.49$ & $2.43 \pm 0.52$ & $1 \cdot 7-4 \cdot 1$ & ns \\
\hline$\partial \mathrm{ELT}(\%$ reduction $)$ & $43 \cdot 6 \pm 34 \cdot 8$ & $34 \cdot 5 \pm 31 \cdot 6$ & - & ns \\
\hline
\end{tabular}

$\mathrm{aCL}=$ anticardiolipin antibodies; $\mathrm{M}-\mathrm{W}=$ Mann-Whitney non-parametric test; LVEDP $=$ left ventricular end-diastolic pressure; APTT = activated partial thromboplastin time; VIII:C = factor VIII activity; vWF:Ag = von Willebrand factor antigen; $\partial \mathrm{ELT}=$ percent reduction of euglobulin lysis time before and after venous occlusion.

Table 2 Prevalence of aCL in pattents with abnormal or normal $\beta$-thromboglobulin. ( $\beta$-TG), platelet factor 4 (PF4) or fibrinopeptide A (FPA) given as absolute numbers of patients for each category. In brackets the percentage of aCL-posittve patients in each subgroup

\begin{tabular}{|c|c|c|c|c|c|c|}
\hline & $\begin{array}{c}\beta-\mathrm{TG} \\
\left(>52 \mathrm{ng} \cdot \mathrm{ml} \quad{ }^{\prime}\right)\end{array}$ & $\begin{array}{c}\beta-\mathrm{TG} \\
\left.(\leqslant 52 \mathrm{ng} \cdot \mathrm{ml})^{\prime}\right)\end{array}$ & $\begin{array}{c}\text { PF4 } \\
(>10 \cdot 4 \mathrm{ng} \cdot \mathrm{ml} \quad)\end{array}$ & $\begin{array}{c}\text { PF4 } \\
(\leqslant 10 \cdot 4 \mathrm{ng} \cdot \mathrm{ml})\end{array}$ & $\begin{array}{c}\text { FPA } \\
(>2 \mathrm{ng} \cdot \mathrm{ml} \quad)\end{array}$ & $\begin{array}{c}\text { FPA } \\
(\leqslant 2 \mathrm{ng} \cdot \mathrm{ml})\end{array}$ \\
\hline $\begin{array}{l}\text { aCL pos } \\
\text { aCL neg }\end{array}$ & $\begin{array}{c}9(176 \%) \\
42\end{array}$ & $\begin{array}{c}26(14.4 \%) \\
155\end{array}$ & $\begin{array}{c}9(19 \cdot 2 \%) \\
38\end{array}$ & $\begin{array}{c}26(14 \cdot 2 \%) \\
157\end{array}$ & $\begin{array}{c}17(15.9 \%) \\
90\end{array}$ & $\begin{array}{c}18(14 \cdot 8 \%) \\
104\end{array}$ \\
\hline
\end{tabular}

and APL units, on the basis of predefined standards ${ }^{[2.8]}$. Since the ECAT probes contained citrated plasma which had been centrifuged and stored for a long period, more than 3 years at $-70^{\circ} \mathrm{C}$, the normal range for aCL was defined separately in plasma taken from 85 healthy blood donors, handled and stored under the same conditions as the samples of the ECAT patients. The mean plus four standard deviations were taken as cut-off points, which were far beyond the 95 th percentiles, in the knowledge that this distribution is not normal (IgG-aCL $<3.6 \mathrm{GPL}$, IgM-aCL $<3.0 \mathrm{MPL}, \mathrm{IgA}-\mathrm{aCL}<5 \cdot 2 \mathrm{APL})$.

\section{FOLLOW-UP}

Patients were followed-up for one and 2 years after initial angiography. Information gathered was concentrated on new myocardial infarctions, other major vascular events and further disease treatment. Except for six patients who did not survive the first year and three patients the second, follow-up was complete.

\section{STATISTICS}

For statistical evaluation, the chi-square test and the non-parametric Mann-Whitney U-test were used as indicated in the results.

\section{Results}

A total of 35 out of 232 evaluated patients (15.1\%) were found to have positive aCL, 12 with $\operatorname{IgG}, 20$ with $\operatorname{IgM}$, three with IgA and two with both $\operatorname{IgG} / \operatorname{IgA}$. Comparing the two groups, aCL positive and aCL negative, for the various laboratory parameters (non-parametric MannWhitney test) no statistically significant differences were found (Table 1). The prevalence of past myocardial infarction was almost the same in aCL-positive and negative groups $(48 \%$ and $38 \%$ respectively, chi-square $P=$ $0 \cdot 32$ ), which makes the groups comparable with respect to recurrent myocardial infarctions.

Patients with previous myocardial infarction (39.5\% of total) showed a higher prevalence of $\mathrm{aCL}$ than others 
Table 3 Frequency of cardiovascular episodes during the two years after angiography in patients grouped according to normal or abnormal $\beta$-thromboglobulin ( $\beta$-TG), platelet factor 4 (PF4) or fibrinopeptide A (FPA) levels given as percent of affected pattents for each subgroup

\begin{tabular}{lcccccc}
\hline & $\begin{array}{c}\beta-\mathrm{TG} \\
\left(>52 \mathrm{ng} \cdot \mathrm{ml}^{-1}\right)\end{array}$ & $\begin{array}{c}\beta-\mathrm{TG} \\
\left(\leqslant 52 \mathrm{ng} \cdot \mathrm{ml}^{-1}\right)\end{array}$ & $\begin{array}{c}\text { PF4 } \\
\left(>10 \cdot 4 \mathrm{ng} \cdot \mathrm{ml}^{-1}\right)\end{array}$ & $\begin{array}{c}\text { PF4 } \\
\left(\leqslant 10 \cdot 4 \mathrm{ng}^{\left.\mathrm{ml} l^{-1}\right)}\right.\end{array}$ & $\begin{array}{c}\text { FPA } \\
\left(>2 \mathrm{ng} \cdot \mathrm{ml}^{-1}\right)\end{array}$ & $\begin{array}{c}\text { FPA } \\
\left(\leqslant 2 \mathrm{ng} \cdot \mathrm{ml}^{-1}\right)\end{array}$ \\
\hline aCL pos & $0 \%$ & $19 \cdot 2 \%$ & $0 \%$ & $19 \cdot 2 \%$ & $5 \cdot 9 \%$ & $22 \cdot 2 \%$ \\
aCL neg & $14 \cdot 3 \%$ & $11 \cdot 6 \%$ & $13 \cdot 2 \%$ & $11 \cdot 5 \%$ & $7 \cdot 8 \%$ & $16 \cdot 3 \%$ \\
\hline
\end{tabular}

(aCL positivity, $18 \cdot 5 \%$ and $13 \cdot 3 \%$ respectively), the difference was not statistically significant (chi-square test, $P=0.29$ ). New myocardial infarctions and/or other vascular thrombotic events were recorded during the 2-year follow-up period. Overall, $14.3 \%$ of aCL positives and $12 \cdot 2 \%$ of aCL negatives suffered from recurrent episodes (chi-square test, $P=0.73$ ). Oral anticoagulation had no effect on recurrencies in aCL-positive and aCL-negative patients.

The influence of positive aCL upon severity of chest pain was tested by comparing the rate of positivity in all patients after having classified them in four groups according to the type of chest pain. Thus $19 \cdot 6 \%$ had resting angina, $64 \%$ effort angina, $8.9 \%$ other chest pain and $7 \cdot 5 \%$ no pain. No statistically significant difference was found between aCL positivity rates in the four groups $(18.2 \%, 11.8 \%, 20 \%$ and $29.4 \%$ respectively, chi-square test $P=0 \cdot 2$ ). Similarly, according to severity of occlusion no statistically significantly different aCL positivity rates were found in the three groups classified as described under Methods $(11.7 \%, 16.7 \%$ and $11.6 \%$ respectively, chi-square test $\boldsymbol{P}=0 \cdot 79$ ).

In Table 2, patients were grouped according to their $\beta$ TG, PF4 or FPA levels. No statistically significant difference in the prevalence of positive aCL was found between those with abnormal and normal values of the above mentioned parameters. Table 3 shows the frequency of recurrent myocardial infarctions or other vascular episodes in the same subgroups during 2 years following angiography. No statistically significant differences were found between those with abnormal and normal activation markers.

\section{Discussion}

Since the description of aCL in the early 1980 s and the observed association with thrombotic disease, various patient groups whose main disease was a thrombotic event have been studied, including those with coronary heart disease ${ }^{[9-11]}$. Hamsten et al ${ }^{[9]}$ found a prevalence of positive aCL in $21 \%$ of young survivors of myocardial infarction. The majority of these aCL-positive patients subsequently suffered a second cardiovascular event, leading the authors to suggest that aCL could be used as a marker for high risk of recurrence of cardiovascular events. Another observation by Eber et al. ${ }^{[10]}$, on 74 unselected males, did not show such a correlation and concluded that aCL are not high-risk markers. Various other groups reported that aCL could accelerate progress of cardiovascular disease or appearance of thrombotic complications ${ }^{[6,11]}$.

In our study on patients with documented coronary heart disease, the prevalence of positive aCL $(15 \cdot 1 \%)$ is similar to that described by others ${ }^{[12]}$. Only three of the 35 positives had $\operatorname{IgA-aCL}$ alone, which diminishes the value of determination of the IgA-class of antibodies. As shown, the presence of $\mathrm{aCL}$ was not accompanied by any statistically significant rise in indicators of haemostasis activation, such as $\beta$-TG, PF4, FPA. The relative risk (ratio of the cumulative incidences in the aCL-positive and negative groups) for suffering a second myocardial infarction or other vascular event in patients with positive aCL was $1 \cdot 17$. Taking only the patients treated with antiplatelet drugs or oral anticoagulants this risk hardly differed at all $(1 \cdot 40)$. Moreover, in those with abnormally high $\beta$-TG, PF4 or FPA we found neither a higher prevalence of aCL nor a higher frequency of recurrent cardiovascular episodes (Table 3). This means that these haemostasis activation markers could not be considered predictive of recurrencies and that no direct relationship between recurrencies and aCL could be postulated. Those with a previous myocardial infarction showed higher $\mathrm{aCL}$ rates compared to those without, which is in accordance with other observations ${ }^{[1]}$. However, among the $\mathrm{aCL}$ positive group, those with a previous myocardial infarction did not show a statistically significantly higher frequency of new cardiovascular events than those without a previous myocardial infarction $(17.6 \%$ vs $11 \cdot 1 \%$, chi-square test $P=0.58$ ). Moreover, in the group with an old myocardial infarction, those with positive aCL did not present statistically significantly higher rates of new cardiovascular events than those with negative $\mathrm{aCL}$ (17.6\% vs $9.3 \%$, chi-square test $P=0.32$ ). It could be that positive aCL also appear after myocardial infarction, pathogenetically linked to cell damage caused by myocardial ischaemia, as it has already been hypothesized by others ${ }^{[1]}$. They did not, however, have a predictive value concerning recurrent cardiovascular events, as shown by our results. aCL positives did not, on the other hand, differ from negatives with respect to the severity of chest pain or coronary stenosis, showing no correlation with the pathogenesis of CHD.

In conclusion, aCL in patients with coronary heart disease were not found to be markers of either progressive cardiovascular disease or recurrent thrombotic events. No relationship could be found between recurrent cardiovascular disease and $\beta$-TG, PF4 or FPA in aCL positive or aCL negative patients. 
We would like to thank Mrs Francine Wolf for her excellent technical assistance.

\section{References}

[1] Tobelem G, Cariou R, Camez A. The lupus anticoagulant and its role in thrombosis. Blood Reviews 1987; 1: 21-4.

[2] Harns EN. Antiphospholipid antibodies. Br J Haematol 1990; 74: $1-9$

[3] Love PE, Santoro SA. Antiphospholipid antibodies Ant1cardiolipin and the lupus anticoagulant in systemic lupus erythematosus (SLE) and in non-SLE disorders. Ann Int Med 1990; 112: 682-98.

[4] Ford PM, Ford SE, Lillicrap DP. Association of lupus ant1coagulant with severe valvular heart disease in systemic lupus erythematosus. J Rheumatol 1988; 15: 597-600.

[5] Hendra TJ, Baguley E, Harris EN et al. Anticardiolipın antibody levels in diabetic subjects with and without coronary artery disease. Postgrad Med J 1989; 65: 140-3.

[6] Mortom KE, Gavaghan TP, Krilis SA et al. Coronary artery bypass graft failure - an autoimmune phenomenon? Lancet $1986 ; 8520$ : 1353-7.
[7] Thomson SG, Calori G, Thomson JM, Haverkate F, Duckert $F$ The impact of sequential quality assessment exercises on laboratory performance: The multicentral ECAT angina pectoris study. Thromb Haemostas 1991; 65: 149-52.

[8] Harris EN, Gharavı AE, Patel P, Hughes GRV. Evaluation of the anticardiolipin test: report of an international workshop held 4 Apnl 1986. Clin Exp Immunol 1987; 68: 215-22.

[9] Hamsten A, Norberg R, Björkholm M, De Faire U, Holm G Antibodies to cardiolipin in young survivors of myocardial infarction: An association with recurrent cardiovascular events. Lancet 1986; 8473: 113-5.

[10] Eber B, Kronberger-Schaffer E, Brussee $\mathrm{H}$ et al. Antıcardiolipin antibodies are no marker for survived myocardial infarction Klin Wochenschr 1990; 68: 594-6.

[11] Sletnes KE, Larsen EW, Stokland O, Wisloff F. Anticardiolipid antibodies detected as anticephalin and anticardiolipin antibodies in patients with acute myocardial infarction: Immunological response to myocardial necrosis? Thromb Res 1990; 59: 675-80.

[12] De Caterina R, D'Ascanio A, Mazzone A et al. Prevalence of anticardiolipin antibodies in coronary artery disease. Am J Cardiol 1990; 65. 922-3. 